International Journal of Advanced Technology in Mechanical, Mechatronics and Materials

(IJATEC)

Vol. 01, No. 1 (2020) 32-38

(C) Institute for Research on Innovation and Industrial System (IRIS)

\title{
The Regression Models of Impact Strength of Coir Coconut Fiber Reinforced Resin Matrix Composite Materials
}

\author{
Muhamad Fitri*a, Shahruddin Mahzan ${ }^{b}$ \\ aMechanical Engineering Department, Faculty of Engineering, Universitas Mercu Buana, Jakarta, Indonesia \\ ${ }^{b}$ Faculty of Mechanical and Manufacturing Engineering, Universiti Tun Hussein Onn Malaysia, Malaysia
}

\begin{abstract}
The need of coconuts in Indonesia is relatively high. The use of large quantities of coconuts produces large amounts of organic waste from coco fiber, which tends to become waste if it is not used to be beneficial for humans.One of the potential uses of coconut fiber is as a reinforcement of natural fibers in polymer matrix composite materials. Recently, the applications of composite materials have been expanded widely including structural angine component which whitstand certain load like impact load. But most of them used synthetic fiber. Although the use of natural fibers as reinforcement in composite materials has been widely studied, their use is still limited because natural fibers have their own advantages and disadvantages. The purpose of this study was to measure the impact strength of specimens of coconut fiber reinforced polymer matrix composite material, and to determine the effect of the length and concentration of coconut fiber on its impact strength. A significant and valid regression model was also generated in this research, that states the relationship between fiber length and fiber content of resin matrix composite material to its impact strength. The result shows that the impact strength of the samples was influenced by fiber content and fiber length. The regression models for the impact strength of resin composite reinforced with coconut fiber is $\mathrm{Y}=4.44+0.180 \mathrm{X} 1-0.52 \mathrm{X} 2$ Where: $\mathrm{Y}=$ Impact Strength $(\mathrm{kJ} / \mathrm{m} 2)$, and X1= Fiber length $(\mathrm{mm})$, and $\mathrm{X} 2=$ Fiber content $(\%)$.
\end{abstract}

Keywords: coconut fiber; fiber content; fiber length; impact strength

DOI: $10.37869 /$ ijatec.v1i1.12

Received 6 March 2020; Accepted 28 March 2020; Available online 30 March 2020

(C) 2020 IRIS Publisher. All rights reserved.

\section{Introduction}

Reinforcement in composite materials can be either particles or fibers. There are many researchers studied the mechanical properties of composite materials. The investigation not only with varies of type of reinforcement, but also by adding some proceses or some materials i.e. treatment, coupling agent, Polysilazane, etc. For example, the effect of polysilazane on the densification and mechanical properties of SICf/SIC composites has been investigated by Noviyanto [1]. The proses in the fiber area were observed for the SICf/SIC composites with the addition of polysilazane. The average grain size of the SICf/SIC composites with and without the addition of polysilazane was 253 and $740 \mathrm{~nm}$, respectively. Indeed, the hardness of the matrix area for SICf/SIC composites with the addition of polysizane $(31.6 \pm 1.8 \mathrm{GPa})$ was higher compared to SICf/SIC composites without polysizane $(27.4 \pm$ $1.6 \mathrm{GPa})[1]$.

Among fibers that are widely used as reinforcement in composite materials are carbon fiber (carbon fiber) and fiberglass (fiberglass). Those are synthetic fibers which cannot be renewed. Therefore, there are many natural fibers being studied currently, which can be renewed, and also widely available around us.

*Corresponding author: muhamad.fitri@mercubuana.ac.id ISSN: 2720-9008 
In fact, many natural fibers become waste and become environmental problems, because they haven't been maximally utilized into useful things for humans. Among many natural fibers that have been studied for their use as reinforcement of composite materials are kenaf fiber, oil palm fiber, pineapple fiber, coconut fiber, etc. [2], [3]. From this study it was found that each natural fiber has different mechanical properties, so the mechanical properties produced by composite materials reinforced by fiber also vary.

The use of natural fibers as reinforcement in polymer composite materials for outdoors applications, tends to undergo the degradation as an effect of various factors such as humidity, temperature, microorganism activity or ultraviolet radiation [4]. However, each fiber in the composite material produces a different degradation response to environmental conditions [5]. Therefore, research on the mechanical properties or degradation of composite materials needs to be done for various types of matrices and different reinforcement.

Indonesia is a producer and user of coconut in large quantities, which of course also produces very large amounts of organic waste from coconut fiber. The availability of abundant coconut fiber tends to increase the waste if it is not used to be beneficial for humans. Therefore, research for the utilization of coconut waste needs to be continuously developed so that coconut fiber waste can be used for something that is more beneficial for humans, which among others is as reinforcement in polymer matrix composite materials.

The application of polymer materials both in form of pure polymers and in composite forms is currently very broad, ranging from household appliances (cookware, cabinets, tables, chairs and so on), recreational and sports equipment (bicycles, tennis and badminton rackets), transportation equipment components (car bumpers, dashboards, interior components and car and aircraft engine components), industrial equipment (pipes, valves, gaskets, to the medical world (fake bones, fake legs, dentures, and even organ organs in fake bodies) humans like fake lungs and lungs) [6-9].

Although the use of natural fibers as reinforcement in composite materials has been widely studied, its utilization is still limited. Because natural fibers have their own advantages and disadvantages compared to synthetic fibers that have been widely used such as glass fiber (fiberglass) or carbon fiber (Carbon fiber) [7]. Therefore the use of natural fibers as reinforcement in composite materials still has to be investigated further, so that their use can be expanded to replace the synthetic fibers used today, not only un load material, but also structure materials which support static load, dynamic load or even impact load.

Several studies have been carried out to utilize natural fibers, including coir coconut fiber for matrix materials, which are mostly matrix base materials in the form of polymeric pellets or granule, so that the manufacturing process requires special equipment or machinery, such as injection molding, mixer brabender, twin screw roll mixer and so on [2], [10-13]. On the one hand, the use of polymer pellets-shaped polymer materials is more widely used. However, the use of polymeric materials in the form of resin and hardener (catalyst) as a matrix has its own advantage i.e. more practical because they do not require special equipment, both for mixing and specimen testing, so that research is easier to be done. Hopefully, this research is a preliminary study on preparing the Coir Coconut fiber polymeric Composite (CCPC) which consists of Resin Polyester and Coir Coconut fiber (CCF).

Polymers have the advantage of certain properties that are not possessed by other materials (metals or ceramics), such as low density, flexibility (flexibility) and high toughness. Therefore, the use of polymers today continues to increase. However, polymers also have lack certain properties, which include low strength when compared to metal materials. To improve this deficiency, some polymer material is added to other materials as reinforcement, in the form of composite materials [14].

Impact testing as well as fatigue testing is included in the classification of dynamic load testing. Several studies on composite materials related to material impact strength have been carried out by [15] who conducted research on the impact strength of polypropylene composite materials reinforced by oil palm fiber. From the study it was found that the $10 \%$ palm fiber content had the highest impact resistance compared to $5 \%$ and $7 \%$. Likewise related to fiber length, $10 \mathrm{~mm}$ palm fiber length has the highest impact capability compared to $5 \mathrm{~mm}$ and $7 \mathrm{~mm}$. Therefore, the research that will be carried out is carried out for coco fiber $8 \%, 10 \%$ and $12 \%$, as well as $8 \mathrm{~mm}$ fiber length, $10 \mathrm{~mm}$ and $12 \mathrm{~mm}$. 
Other researchers [10] and [2] found that the mechanical properties of composite materials are influenced by fiber content. If the fiber content is too low, the composite material will not improve the mechanical properties of the material.

Fiber length in the composite material also affects the mechanical properties of the composite material produced. If the fiber length is too short, then the fiber does not function as a reinforcement, but only as a filler [16].

Based on the explanation of the background of study explained above, It is need to be investigated the impact strength of polymer matrix reinforced coconut fiber, and the influence of the fiber length and content of coconut fiber on the polymer matrix composite material on impact strength. As preliminary study, the regression model that can be made stating the effect of fiber size and coir fiber content on resin matrix composite material on significant and valid impact strength. This Study focus on generating the regression model of the influence of fiber length and fiber contents to impact resistance of CCPC. The morphological properties of CCPC were also investigated and were examined using Optical Microscopy (OM).

\section{Research Methodology}

\subsection{The research flow}

The research begins with the preparation of tools and materials for preparation specimens. Then do the impact test and OM (Optical Microscopy) on the samples. The impact strength [17] were calculated from the impact test Data by using the equation below:

$$
a_{c N}=\frac{E_{c}}{h b_{N}} \cdot 10^{3}
$$

where

$a_{c N}$ is the Charpy impact strength, in kilojoules per square meter,

$E_{c}$ is the corrected energy, in joules, absorbed by breaking the test specimen,

$h$ is the thickness, in millimetres, of the test specimen,

$b_{N}$ is the remaining width, in millimetres, of the test specimen.

The impact strength results were used for data analysis. Then a regression model of impact strength was generated base on the impact strength result. The variable include in the regression model were fiber length and fiber content.

In this study several problem boundaries are used to limit the scope of the research to be conducted. The limitations of these problems include:

1. The length of fiber to be studied is limited to $8 \mathrm{~mm}, 10 \mathrm{~mm}$ and $12 \mathrm{~mm}$.

2. The fiber content in composite materials is limited to $1.8 \%, 2.3 \%$ and $2.8 \%$ by weight.

3. The resin material used is Polyester resin material.

4. The coconut fiber used was the remaining dry coconut coir.

\subsection{Material and equipment}

The equipment used in this study are as follows:

1. Molds for impact specimen preparation.

2. Impact test equipment for plastic / polymer materials.

3. Optical Microscopy (OM)

The materials used in this study are:

1. Resin and catalyst.

2. Dry coconut coir fiber

\subsection{Specimens preparation}

The specimens size according to ISO 179-1: 2000 standards. There are 2 factors studied, namely fiber length and fiber content, each of which consists of 3 levels as follows:

1. Fiber length consists of: $8 \mathrm{~mm}, 10 \mathrm{~mm}$ and $12 \mathrm{~mm}$. 


\section{The fiber content consists of $1.8 \%, 2.3 \%$ and $2.8 \%$.}

The study was designed to use the full factorial design, so the number of combinations of sample types that must be prepared are: $3 \times 3=9$ samples combinations, as shown in Table 1. Each combination was prepared 5 samples. So that the total number of samples is 45 samples.

Table 1. Full factorial design of experiment

\begin{tabular}{ccc}
\hline Sample code & $\begin{array}{c}\text { Panjang Serat } \\
(\mathbf{m m})\end{array}$ & $\begin{array}{c}\text { Kandungan Serat } \\
\mathbf{( \% )}\end{array}$ \\
\hline 0818 & 8 & 1.8 \\
0823 & 8 & 2.3 \\
0828 & 8 & 2.8 \\
1018 & 10 & 1.8 \\
1023 & 10 & 2.3 \\
1028 & 10 & 2.8 \\
1218 & 12 & 1.8 \\
1223 & 12 & 2.3 \\
1228 & 12 & 2.8 \\
\hline
\end{tabular}

Furthermore, the specimen was made with the following procedure:

1. Pour the resin into the mold.

2. Combine resin and coconut coir fiber according to the size and content specified. Make sure the fibers are distributed evenly throughout the mold section.

3. Add the catalyst according to the reference to the material and stir until evenly distributed.

4. Let the material harden, then remove it from the mold.

5. Make sure the specimen size is according to ISO 179-1: 2000 standards.

\subsection{Impact test and Optical Microscopy (OM)}

The impact test carried out using Charpy impact test equipment of University of Batam, while the morphology the specimens observed using optical microscopy of Mechanical engineering laboratory of Mercu Buana University. The impact test results are in the form of impact energy from each specimen. This data is then used to calculate the impact strength of each specimen and the average impact strength for each condition.

\subsection{Generating regression model}

Regression model is a model in the form of mathematical equations obtained from the results of processing research data. This model consists of independent variables and dependent variables. With this model, then it can be simulated how much the value of the independent variable to get the value of a particular dependent variable. For example, if the independent variable is fiber length and fiber content, the dependent variable is impact strength. So, by using a regression model, it can be simulated how much the fiber size and fiber content must be made to get a certain impact strength value from the composite material.

In this study regression analysis was conducted to model the relationship between fiber length and fiber content on the impact strength of coconut coir resin composite material. The general form of the regression model that will be made later is as follows:

$$
K_{I}=a_{1}+b_{1} \cdot X_{1}+b_{2} \cdot X_{2}
$$

where:

$K_{I}=$ material impact strength

$a_{1}=$ Constants

$b_{1}=$ Coefficient $x_{1}$

$b_{2}=$ Coefficient $x_{2}$

$x_{1}=$ variable fiber length

$x_{2}=$ variable fiber content 
With this regression model, the mathematical relationship between fiber length and coconut fiber content can be obtained on the resin composite material on its impact strength.

Furthermore, this regression model tested its significance and validated it by obtaining a valid regression model. So that this regression model can be used for further research. So that in further research, if desired material with high impact strength can be obtained first by optimizing the model.

This regression model can then be used to predict the impact strength of the material with varying concentrations of fiber content and fiber length variations. By entering fiber length $\left(x_{1}\right)$ and concentration of fiber content $\left(x_{2}\right)$ in the regression model, we can predict the value of impact strength of the material to be produced on the resin matrix composite material.

\section{Results and Discussions}

The result of impact tests is the impact energy of the samples. Every condition consist of 5 samples and the average of the impact energy of every condition were input in Table 2 . Then, these impact energies were used to calculate the impact strength of the samples as shown in Table 2. Table 2 shows that the samples with code 1018 (10 mm fiber length and $1.8 \%$ fiber content) has the lowest impact strength, $0,99 \mathrm{~kJ} / \mathrm{m}^{2}$, while the samples with code 0818 has the best impact strength $2,78 \mathrm{~kJ} \cdot \mathrm{m}^{2}$.

Table 2. The impact energy and the impact strength of the specimen

\begin{tabular}{ccccc}
\hline $\begin{array}{c}\text { Specimen } \\
\text { code }\end{array}$ & $\begin{array}{c}\text { Fiber length } \\
(\mathrm{mm})\end{array}$ & $\begin{array}{c}\text { Fiber } \\
\text { content }(\%)\end{array}$ & $\begin{array}{c}\text { Impact } \\
\text { energy }(\mathrm{J})\end{array}$ & $\begin{array}{c}\text { Impact strength } \\
(\mathrm{kJ} / \mathrm{m} 2)\end{array}$ \\
\hline 0818 & 8 & 1.8 & 0.089 & 2.78 \\
0823 & 8 & 2.3 & 0.057 & 1.78 \\
0828 & 8 & 2.8 & 0.032 & 0.99 \\
1018 & 10 & 1.8 & 0.024 & 0.75 \\
1023 & 10 & 2.3 & 0.048 & 1.49 \\
1028 & 10 & 2.8 & 0.057 & 1.78 \\
1218 & 12 & 1.8 & 0.051 & 1.59 \\
1223 & 12 & 2.3 & 0.032 & 1.01 \\
1228 & 12 & 2.8 & 0.025 & 0.79 \\
\hline
\end{tabular}

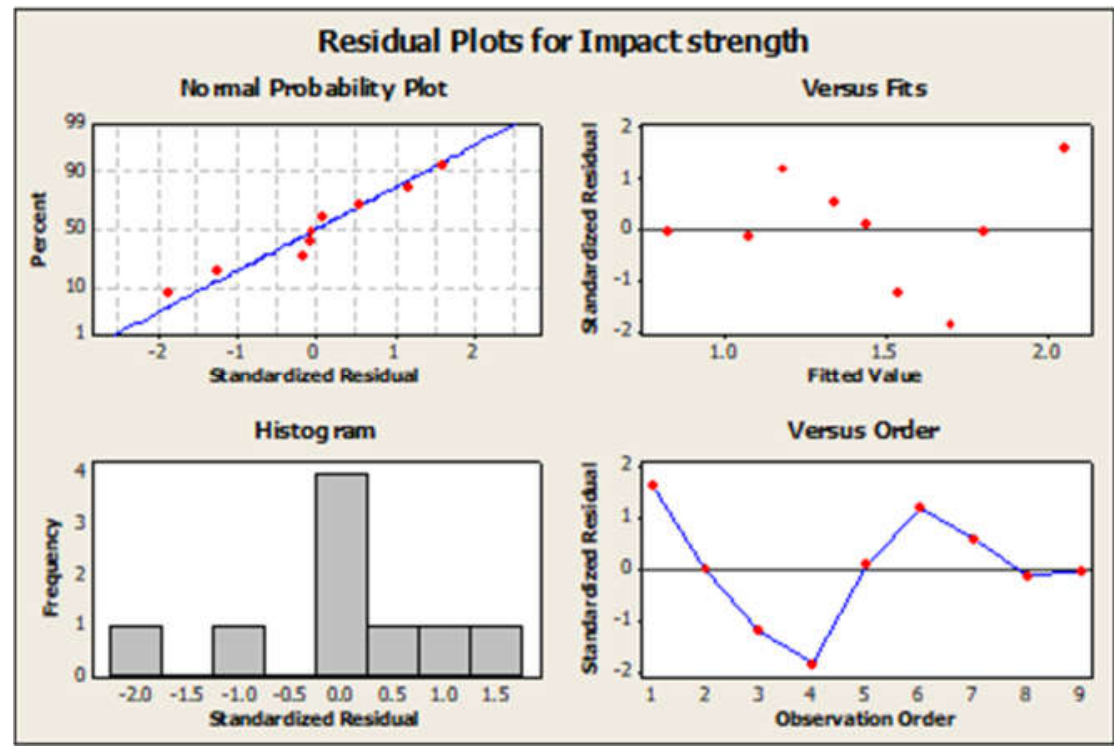

Figure 1. Residual plots for impact strength

The know the influence of fiber content and fiber length to impact strength, the data in Table 2 were analysed statistically using minitab application. The regression equation for Impact strength of specimens was obtained: 


$$
Y=4.44+0.180 X_{1}-0.520 X_{2}
$$

Where:

$\mathrm{Y}=$ Impact strength $\left(\mathrm{kJ} / \mathrm{m}^{2}\right)$

$X_{1}=$ Fiber length $(\mathrm{mm})$

$X_{2}=$ Fiber content $(\%)$

Figure 1 was graphically validated, and the regression model was found to meet the analysis assumption. The upper left graph in Figure 1 is the normal probability plot graph. This graph shows that the residuals of all points tend to form a straight line, thus indicating that the data was normally distributed. This normally distributed assumption is also supported by the histogram in the lower left. The residual versus fit plot in the upper right shows that the residuals are randomly scattered around zero. This indicates that the relationship is linear. There is no trend formed by residuals versus order plot in the lower right graph, which indicates that the residuals are independent, and the regression assumptions are satisfied.

\section{Conclusions}

Based on the result of this research, can be concluded that:

1. The fiber length and fiber content influence the impact strength of resin composite reinforced with coconut fiber.

2. The regression equation has been generated. By this equation, the impact strength of composite material can be predicted.

3. The regression model of the samples in this study is $Y=4.44+0.180 X_{1}-0.52 X_{2}$ where $Y=$ Impact Strength $\left(\mathrm{kJ} / \mathrm{m}^{2}\right), X_{1}=$ Fiber length $(\mathrm{mm})$ and $X_{2}=$ Fiber content $(\%)$.

\section{References}

[1] Nofiyanto A (2020). The Effect of Polysilazane on the Densification and Mechanical Properties of $\operatorname{SIC}_{\mathrm{f}} / \mathrm{SIC} \quad$ Composites. Sinergi. Vol $24 . \quad$ No.1. 11-6. http://dx.doi.org/10.22441/sinergi.2020.1.002.

[2] Al-mosawi, A. I. (2014). Mechanical properties of composite material reinforcing by naturalsynthetic fibers. Academic Research International, 3(May), 108-112. http://www.savap.org.pk/journals/ARInt./Vol.3(3)/2012(3.3-13).pdf

[3] Adekanye, T., Samuel, O. D., Agbo, S., \& Adekanye, T. A. (2015). Assessing Mechanical Properties of Natural Fibre Reinforced Composites for Engineering Applications. Journal of Minerals and Materials Characterization and Engineering, (January 2012), 780-784. https://cyberleninka.org/article/n/379053

[4] Azwa, Z. N., \& Yousif, B. F. (2013). Characteristics of kenaf fi bre / epoxy composites subjected to thermal degradation. Polymer Degradation and Stability, 98(12), 2752-2759. https://doi.org/10.1016/i.polymdegradstab.2013.10.008

[5] Awaja, F., \& Pigram, P. J. (2009). Surface molecular characterisation of different epoxy resin composites subjected to UV accelerated degradation using XPS and ToF-SIMS. Polymer $\begin{array}{lll}\text { Degradation } \quad \text { and } & \text { Stability, }\end{array}$ https://doi.org/10.1016/i.polymdegradstab.2009.01.001

[6] Srinivasan, S. (2001). Polymers in Automobiles. In W. Brostow (Ed.), Performance of Plastics (pp. 629-652). Munich: Hanser Publishers.

[7] Strong, A. B. (2006). Plastics: Materials and Processing. Science and Technology of Advanced Materials (third edit, Vol. 14). New Jersey: Prentice Hall. https://doi.org/10.1088/14686996/14/4/045008

[8] Gay, D. (2014). Composite Materials Design and Applications (third Edit). Boca Raton: CRC Press. https://www.crcpress.com/Composite-Materials-Design-and-Applications-ThirdEdition/Gay/p/book/9781466584877 
[9] Alfa S, Sundari R, Aziz AS, Rashid NAA, Gunawan W (2018). Development of Ammoniumselective Electrode Based on PVC/MB28 Membrane. International Conference on Design, Engineering and Computer Sciences. 453. https://iopscience.iop.org/issue/1757-899X/453/1

[10] El-shekeil, Y. A., Sapuan, S. M., Abdan, K., \& Zainudin, E. S. (2012). Influence of fiber content on the mechanical and thermal properties of Kenaf fiber reinforced thermoplastic polyurethane composites. Materials and Design, 40, 299-303. https://doi.org/10.1016/j.matdes.2012.04.003

[11] Izani, M. A. N., Paridah, M. T., Anwar, U. M. K., Nor, M. Y. M., \& H'ng, P. S. (2013). Effects of fiber treatment on morphology, tensile and thermogravimetric analysis of oil palm empty fruit bunches fibers, 45, 1251-1257. https://doi.org/10.1016/j.compositesb.2012.07.027

[12] Mamun, A. A., Heim, H., Hossen, D., Kim, T. S., \& Ahmad, S. H. (2013). PLA and PP composites with enzyme modified oil palm fibre : A comparative study. Composites Part A, 53, 160-167. https://doi.org/10.1016/j.compositesa.2013.06.010

[13] Gozde, N., Ahsan, B., Mansour, S., \& Iyengar, S. R. (2014). Mechanical performance and durability of treated palm fiber reinforced mortars. International Journal of Sustainable Built Environment, 2(2), 131-142. https://doi.org/10.1016/j.ijsbe.2014.04.002

[14] Chanda, M., \& Roy, S. K. (2008). Plastics Fundamentals, Properties, and Testing _ Taylor \& Francis Group (1st Editio). Boca Raton: CRC Press. https://www.crcpress.com/PlasticsFundamentals-Properties-and-Testing/Chanda-Roy/p/book/9781420080605

[15] Fitri, M., \& Mahzan, S. (2016a). The effect of fibre content, fibre size and alkali treatment to Charpy impact resistance of Oil Palm fibre reinforced composite material. IOP Conference Series: Materials Science and Engineering, 160(1). https://doi.org/10.1088/1757899X/160/1/012030

[16] Joffre, T., Miettinen, A., Berthold, F., \& Gamstedt, E. K. (2014). X-ray micro-computed tomography investigation of fibre length degradation during the processing steps of short-fibre composites. COMPOSITES SCIENCE AND TECHNOLOGY, 105, 127-133. https://doi.org/10.1016/j.compscitech.2014.10.011

[17] International organization for standardization. (2001). Plastics - Determination of Charpy impact $\quad$ properties. ISO 179-1, (1110). https://www.iso.org/standard/44852.html\#: :text=ISO\%20179\%2D1\%3A2010\%20specifi es,and $\% 20$ the $\% 20$ type $\% 20$ of $\% 20$ notch. 